\title{
A preliminary study of the use of bioimpedance in the screening of squamous tongue cancer
}

This article was published in the following Dove Press journal:

International Journal of Nanomedicine

16 March 2010

Number of times this article has been viewed

\section{Congo Tak-Shing Ching ${ }^{1,2}$ \\ Tai-Ping Sun ${ }^{1,2}$ \\ Su-Hua Huang ${ }^{3}$ \\ Chin-Sung $\mathrm{Hsiao}^{4}$ \\ Ching-Haur Chang ${ }^{4}$ \\ Shiow-Yuan Huang ${ }^{4}$ \\ Yi-Juai Chen ${ }^{5}$ \\ Chi-Sheng Cheng ${ }^{6}$ \\ Hsiu-Li Shieh ${ }^{2}$ \\ Chung-Yuan Chen ${ }^{2}$ \\ 'Graduate Institute of Biomedicine and Biomedical Technology, National Chi Nan University, Nantou, Taiwan; 2Department of Electrical Engineering, National Chi Nan University, Nantou, Taiwan; ${ }^{3}$ Department of Biotechnology, Asia University, Taichung, Taiwan; ${ }^{4}$ Department of Photonics and Communication Engineering, Asia University, Taichung, Taiwan; \\ ${ }^{5}$ Department of Oral and Maxillofacial Surgery, Chung Shan Medical University Hospital, Taichung, Taiwan; ${ }^{6}$ Department of Oral and Maxillofacial Surgery, Taichung Veterans General Hospital, Taichung, Taiwan}

Correspondence: Tai-Ping Sun Department of Electrical Engineering, National Chi Nan University, No. I, University Road, Puli, Nantou County 5456 I, Taiwan

Fax +886-492912434

Tel +886-4929l0960 Ext 4000

Email tps@ncnu.edu.tw

\begin{abstract}
Oral cancers are the 11th most common malignancy reported worldwide, accounting for $3 \%$ of all newly diagnosed cancer cases, and one with high mortality ratios among all malignancies. The objective of this study was to study the electrical properties of cancerous tongue tissue (CTT) and normal tongue tissue (NTT). Five tongue cancer patients participated in this study. A disposable probe incorporating four silver electrodes was used to measure the electrical properties of CTT and the surrounding NTT of patients. Measurements were performed at six frequencies: $20 \mathrm{~Hz} ; 50 \mathrm{kHz} ; 1.3 \mathrm{MHz} ; 2.5 \mathrm{MHz} ; 3.7 \mathrm{MHz}$; and $5 \mathrm{MHz}$, with the amplitude of the applied voltage limited to $200 \mathrm{mV}$. Four measurement parameters of impedance (Z), phase angle $(\theta)$, real part of impedance $(R)$, and imaginary part of impedance $(X)$ of tongue tissue were assessed to see if there was any significant difference in the values obtained in CTT and surrounding NTT. The intraclass correlation coefficient showed that all measurements were reliable. A significant difference $(P<0.05$ for the four measurement parameters) was found at $50 \mathrm{kHz}$ between CTT and surrounding NTT. It was also found that $\mathrm{Z}$ and R of CTT were generally smaller than that of surrounding NTT. In conclusion, bioimpedance at a particular frequency is a potentially promising technique for tongue cancer screening.
\end{abstract}

Keywords: bioimpedance, tongue, cancer, noninvasive, detection, screening

\section{Introduction}

Oral cancer is one of the most frequently occurring cancers worldwide and has a higher proportion of deaths per number of cases than, breast cancer or cervical cancer; because of late detection. Diagnostic delay has been shown to be a significant factor in disease progression. The time between diagnosis of premalignant lesion and malignant transformation is relatively short. Studies have demonstrated transformation occurred as soon as 6 months from time of biopsy to definitive cancer diagnosis. ${ }^{1}$

The term oral cancer encompasses a diverse group of tumors arising from the oral cavity (ie, lip, tongue, floor of the mouth, gums, and soft palate). The most common sites for oral cancer are the tongue and floor of the mouth. Oral cancer is a major public health issue in almost all countries of the world. Cancers of the oral cavity accounted for 274,000 cases worldwide in 2002, with almost two thirds occurring in men. ${ }^{2}$ According to the figures reported in 2004 by Bureau of Health Promotion, Department of Health, R.O.C. (Taiwan), the prevalence of oral cancer in Taiwan has increased $160 \%$ in the past ten years and the mortality has increased $110 \%$ with the average age of 53. Incidence rates in men are high in Western Europe, Southern Europe, Southern Asia, Southern Africa, and Australia/New Zealand. ${ }^{2}$ In females the incidence is relatively high in southern Asia. ${ }^{2}$ 
The routine clinical practice to detect oral cancer is initially made by visual inspection followed by the biopsy of any suspicious lesions found. However, oral cancer can go unnoticed, and therefore visual inspection is incapable of effectively screening or detecting cancerous changes in the oral cavity. Such delay in diagnosis may adversely affect the patients' prognosis. A a result most oral cancer patients present with advanced disease, have secondary tumors and suffer from other co-morbidities. Biopsy is an invasive method and this approach increases the emotional trauma to the patient waiting for a diagnosis. New methods for reliable, low-cost, noninvasive, and real-time screening or detection of oral cancer are thus warranted.

In recent times, 'light biopsy' with various optical methods, such as fluorescence, ${ }^{3,4}$ Raman $^{5}$ and elastic scattering ${ }^{6}$ spectroscopy, have been investigated to establish techniques for the screening and detection of oral cancer. However, none of these techniques has been proved to be totally reliable both in screening or detecting oral cancer, and limitations still exist. For example, fluorescence spectroscopy can be significantly hindered by the presence of tissue scattering and absorption, and fails to account for confounding factors such as inflammatory changes that may produce fluorescence emission spectra, resulting in false-positive results. Raman spectroscopy shares the major limitation of other point-detection methods in that only a very small tissue volume is interrogated and it can be very sensitive to mucosal movement. Also the Raman spectroscopy technique is expensive, complex and difficult to adapt for in vivo use due to superimposed optical fiber and auto-fluorescence complicating the spectra. Elastic scattering spectroscopy is insensitive and imaging is very difficult. Source and detector fibers need to be sufficiently separated for the diffusion approximation to be valid, ie, $>0.5 \mathrm{~cm}$, but at this distance the technique would be insensitive to the size and shape of scattering centers. The intention of this study was therefore to investigate a new approach, namely bioimpedance, for reliable, low-cost, noninvasive, and real-time screening or detection of tongue cancer.

Bioimpedance is the measurement of the impedance signal, which is obtained by injecting a low-level sinusoidal current into the tissue and measuring the voltage drop generated by the tissue impedance. A bioimpedance signal gives information about electrochemical processes in the tissue and hence can be used for characterizing the tissue or for monitoring physiological changes. The electrical properties of tissue vary with the frequency of the applied electric field as seen from $\alpha$-, $\beta$ - and $\gamma$-dispersion. ${ }^{7}$ The $\alpha$-dispersion occurs at low frequencies $(10 \mathrm{~Hz}-10 \mathrm{kHz})$ and is mainly affected by the ionic environment that surrounds the cells. The $\beta$-dispersion $(10 \mathrm{kHz}-10 \mathrm{MHz})$ is a structure relaxation. At higher frequencies, the $\gamma$-dispersion is found to be related to water molecules. The $\alpha$ - and $\beta$-dispersion regions are more interesting in medical applications, since most changes between pathological and normal tissue occur in this range. ${ }^{8}$ In this study the electrical properties of cancerous tongue tissue and surrounding normal tongue tissue were measured at $\alpha$ - and $\beta$-dispersion regions.

Bioimpedance is well established and has been introduced into clinical investigation of breast cancer ${ }^{9-12}$ and cervical cancer. ${ }^{13-15}$ In 1999, TransScan TS2000 (TransScan Medical, Ltd., Sweden), an impedance-imaging device for breast cancer detection, was approved for use by the American Food and Drug Administration as an adjunct to mammography for the evaluation of equivocal breast lesions. ${ }^{16} \mathrm{At}$ present, no studies using bioimpedance for the screening or detection of cancerous changes in the oral cavity have been reported in the literature. Many in vitro ${ }^{17-20}$ and in vivo ${ }^{9-12}$ studies showed that there are significant differences in electrical impedance between normal and malignant human breast tissues; malignant breast tumors have typically lower electrical impedance than surrounding normal tissues. The change in the electrical impedance of malignant tissue in comparison to surrounding healthy tissues are attributed to increased cellular water and salt content, altered membrane permeability, changed packing density, and orientation of cells. ${ }^{21}$ Other studies have also demonstrated that there are significant differences in electrical impedance between benign and malignant breast tumors. ${ }^{911,18,22}$ Therefore, the hypothesis of this study was that cancerous tongue tissue has lower impedance compared with surrounding normal tongue tissue.

The aim of this study was to investigate the electrical properties of cancerous tongue tissue and normal tongue tissue, in order to establish a new approach, namely bioimpedance, for reliable, low-cost, noninvasive, and real-time screening or detection of tongue cancer.

\section{Materials and methods}

Five tongue cancer patients ( 4 men and 1 woman; T1 and T2 stages of oral squamous cell carcinoma) were recruited in this study. The study was approved by The Institutional Review Board of Taichung Veterans General Hospital. Informed consent was obtained from each patient.

Four electrical properties of tongue tissue were measured and they were: impedance $(Z)$; phase angle 
$(\theta)$; real part of impedance $(\mathrm{R})$; and imaginary part of impedance $(\mathrm{X})$. Measurements were made using a disposable probe (Figure 1) with four 1-mm-diameter silver electrodes ( $2 \mathrm{~mm}$ between electrode centers) mounted in square configuration on a plastic bar $(5 \mathrm{~mm}$ width $\times 3 \mathrm{~mm}$ thick $\times 100 \mathrm{~mm}$ long). The disposable probe was connected to an impedance analyzer (Precision Impedance Analyzer WK6420C, Wayne Kerr Electronics Ltd, Chichester, UK) for all measurements. On the other hand, the probe was evaluated in saline of known electrical conductivity and had an accuracy of $\pm 0.2 \Omega$ on measuring resistance.

\section{Measurement procedures}

Electrical properties of tongue tissue measurements were made with patients sitting on a chair. The disposable probe was placed in two separate positions on the patient's tongue: 1) on cancerous tongue tissue (CTT) and 2) on surrounding normal tongue tissue (NTT). The definition of surrounding NTT in this study is defined as the tongue tissue $10 \mathrm{~mm}$ away from the regional edge of the CTT.

At each position, electrical properties of tongue tissue measurements were made at six frequencies: $20 \mathrm{~Hz} ; 50 \mathrm{kHz}$; $1.3 \mathrm{MHz} ; 2.5 \mathrm{MHz} ; 3.7 \mathrm{MHz}$; and $5 \mathrm{MHz}$, with the amplitude of the applied voltage limited to $200 \mathrm{mV}$. In all cases, three separate sets of measurement of a position were made in succession in order to check reliability of the measurements.

Prior and subsequent to each patient measurement, their oral temperatures were orally measured using body-temperature thermometer (Terumo Digital Clinical Thermometer C402, Terumo Corporation Tokyo, Japan).

\section{Statistical analysis}

Intraclass correlation coefficient (ICC) was used to evaluate intrarater reliability (ICC 3,1) for the measurement of $\mathrm{Z}$, $\theta, \mathrm{R}$, and $\mathrm{X}$. Paired-sample $\mathrm{t}$ test was used to determine whether there were significant differences between CTT and surrounding NTT for the test parameters of Z, $\theta$, R, and X at each frequency. All statistical analyses were carried out using SPSS software with the level of statistical significance set at 0.05 .

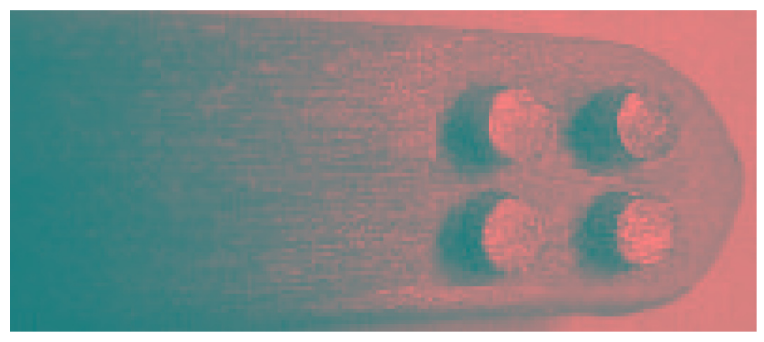

Figure I The four-electrode disposable probe.

\section{Results}

Five tongue cancer patients participated in this study. Their pre- and post-experimental oral temperatures were recorded and summarized in Table 1. Patients' oral temperature ranged from $36.6^{\circ} \mathrm{C}$ to $36.8^{\circ} \mathrm{C}$. No statistical significant difference was found on patients' pre- and post-experimental oral temperatures.

ICC for the intrarater reliability (ICC 3,1) for the measurement of electrical parameters $(Z, \theta, R$, and $X)$ of tongue tissues at different frequencies are summarized in Table 2. ICC ranged from 0.83 to 1.00 . All electrical parameter measurements at each frequency for CTT and surrounding NTT had ICC $\geq 0.93$, except surrounding NTT measurements of phase angle at $20 \mathrm{~Hz}(\mathrm{ICC}=0.88)$ and that of real part of impedance at $50 \mathrm{kHz}(\mathrm{ICC}=0.83)$ and $5 \mathrm{MHz}(\mathrm{ICC}=0.87)$.

The electrical properties of tongue tissues at different frequencies are summarized in Table 3 and Figures 2 and 3. It was found that the impedance of CTT and surrounding NTT decreased as the measurement frequency increased. The impedance of CTT was generally smaller than that of surrounding NTT. Moreover, the impedance of CTT was found to be significantly smaller than that of surrounding NTT at $20 \mathrm{~Hz}(P<0.05)$ and $50 \mathrm{kHz}(P<0.001)$.

On the other hand, it was found that the phase angle of CTT and surrounding NTT reduced as the measurement frequency increased. The phase angle of CTT was usually larger than that of surrounding NTT. Furthermore, the phase angle of CTT was found to be significantly larger than that of surrounding NTT at $50 \mathrm{kHz}(P<0.05)$.

The real part of impedance of CTT and surrounding NTT was found to decline as the measurement frequency

Table I Pre- and post-experimental oral temperature of patients

\begin{tabular}{lllllll}
\hline Patient & & $\mathbf{I}$ & $\mathbf{2}$ & $\mathbf{3}$ & $\mathbf{4}$ & $\mathbf{5}$ \\
\hline Oral Temp ( $\left.{ }^{\circ} \mathbf{C}\right)$ & Pre-experimental & 36.6 & 36.7 & 36.8 & 36.6 & 36.7 \\
& Post-experimental & 36.6 & 36.8 & 36.8 & 36.6 & 36.7 \\
\hline
\end{tabular}


Table 2 Estimation of intra-rater reliability (ICC 3,I) for the measurement of impedance $(Z)$, phase angle $(\theta)$, real part of impedance $(\mathrm{R})$, and imaginary part of impedance $(X)$ of cancerous and surrounding normal tongue tissues at different frequencies

\begin{tabular}{|c|c|c|c|c|c|c|c|c|}
\hline \multirow[t]{2}{*}{ Freq $(\mathrm{Hz})$} & \multicolumn{4}{|c|}{ Cancerous tongue tissue } & \multicolumn{4}{|c|}{ Surrounding normal tongue tissue } \\
\hline & $\mathbf{Z}$ & $\theta$ & $\boldsymbol{R}$ & $x$ & $\mathbf{Z}$ & $\theta$ & $\boldsymbol{R}$ & $x$ \\
\hline 20 & 0.99 & 0.99 & 0.99 & 0.99 & 0.99 & 0.88 & 0.99 & 0.99 \\
\hline $50 \mathrm{k}$ & 0.98 & 0.95 & 0.97 & 0.99 & 0.95 & 0.93 & 0.83 & 0.95 \\
\hline I.3 M & 1.00 & 0.99 & 0.99 & 1.00 & 0.99 & 0.98 & 0.98 & 0.99 \\
\hline $2.5 \mathrm{M}$ & 1.00 & 1.00 & 1.00 & 1.00 & 1.00 & 1.00 & 0.99 & 1.00 \\
\hline $3.7 \mathrm{M}$ & 1.00 & 1.00 & 1.00 & 1.00 & 0.99 & 0.98 & 0.95 & 0.99 \\
\hline $5 \mathrm{M}$ & 1.00 & 1.00 & 1.00 & 1.00 & 0.99 & 0.90 & 0.87 & 0.99 \\
\hline
\end{tabular}

increased. It was also found that the real part of impedance of CTT was significantly smaller than that of surrounding NTT at $20 \mathrm{~Hz}(P<0.05)$ and $50 \mathrm{kHz}(P<0.05)$.

The imaginary part of impedance of CTT and surrounding NTT was found to increase as the measurement frequency increased. The imaginary part of impedance of CTT was generally larger than that of surrounding NTT. In addition, the imaginary part of impedance of CTT was found to be significantly larger than that of surrounding NTT at $20 \mathrm{~Hz}$ $(P<0.05)$ and $50 \mathrm{kHz}(P<0.001)$.

\section{Discussion}

In this study, patients' pre- and post-experimental oral temperatures were measured as impedance of tissue varies with temperature. ${ }^{23}$ Results showed that only patient 2 had changed $\left(0.1^{\circ} \mathrm{C}\right)$ in oral temperature from $36.7^{\circ} \mathrm{C}$ to $36.8^{\circ} \mathrm{C}$ after the experiment. Such temperature changes might be due to the patient's real oral temperature change or due to instrumentation error during measurement as the body-temperature thermometer has the accuracy of $\pm 0.1^{\circ} \mathrm{C}$. For the other patients, their pre- and post-experimental oral temperatures were constant. Among the patients, the lowest and the highest oral temperature were $36.6^{\circ} \mathrm{C}$ and $36.8^{\circ} \mathrm{C}$ respectively, with a temperature difference of only $0.2^{\circ} \mathrm{C}$. Because the oral temperature difference among patients was not large, the effect of temperature on patients' impedance was assumed to be minimal.

The ICC is a measure that can be used to quantify the reproducibility of a variable. At the same time, it is a measure of the homogeneity within groups (CTT and surrounding NTT) of replicate measurements relative to the total variation between groups. Portney and Watkins ${ }^{24}$ have suggested that ICC values above 0.75 are indicative of good reliability and those below 0.75 should be considered as poor to moderate. Portney and Watkins ${ }^{25}$ state; "For many clinical measurements, reliability should exceed 0.90 to ensure reasonable validity." All the $\operatorname{ICC}(3,1)$ measurements in this study, except surrounding NTT measurements of phase angle at

Table 3 Impedance $(Z)$, phase angle $(\theta)$, real part of impedance $(R)$, and imaginary part of impedance $(X)$ of tongue tissues measured at different frequencies. Results were expressed as means and standard deviations. Standard deviations were stated in parentheses

\begin{tabular}{|c|c|c|c|c|c|c|c|c|}
\hline \multirow{2}{*}{$\begin{array}{l}\text { Freq } \\
(\mathrm{Hz})\end{array}$} & \multicolumn{4}{|c|}{ Cancerous tongue tissue } & \multicolumn{4}{|c|}{ Surrounding normal tongue tissue } \\
\hline & $Z$ (ohm) & $\theta$ (Deg) & $R$ (ohm) & $X(\mathrm{ohm})$ & $Z$ (ohm) & $\theta$ (Deg) & $R$ (ohm) & $X(\mathrm{ohm})$ \\
\hline 20 & $\begin{array}{c}4317.92 \\
(3639.79)\end{array}$ & $\begin{array}{l}-22.74 \\
(6.52)\end{array}$ & $\begin{array}{l}4049.90 \\
(3546.48)\end{array}$ & $\begin{array}{l}-1440.95 \\
(912.31)\end{array}$ & $\begin{array}{l}\text { I277|.50 } \\
(6459.79)\end{array}$ & $\begin{array}{l}-13.40 \\
(0.88)\end{array}$ & $\begin{array}{l}|2432.4| \\
(630 \mid .02)\end{array}$ & $\begin{array}{l}-2918.89 \\
(1432.33)\end{array}$ \\
\hline $50 \mathrm{k}$ & $\begin{array}{c}372.02 \\
(141.47)\end{array}$ & $\begin{array}{l}-37.97 \\
(6.13)\end{array}$ & $\begin{array}{l}290.08 \\
(106.61)\end{array}$ & $\begin{array}{l}-228.91 \\
(121.27)\end{array}$ & $\begin{array}{l}782.93 \\
(109.58)\end{array}$ & $\begin{array}{l}-49.78 \\
(4.47)\end{array}$ & $\begin{array}{l}500.77 \\
(34.46)\end{array}$ & $\begin{array}{l}-599.18 \\
(121.27)\end{array}$ \\
\hline $1.3 \mathrm{M}$ & $\begin{array}{l}75.04 \\
(23.94)\end{array}$ & $\begin{array}{l}-71.12 \\
(15.38)\end{array}$ & $\begin{array}{l}22.96 \\
(19.72)\end{array}$ & $\begin{array}{l}-69.29 \\
(13.86)\end{array}$ & $\begin{array}{l}85.28 \\
(13.63)\end{array}$ & $\begin{array}{l}-76.75 \\
(6.37)\end{array}$ & $\begin{array}{l}18.90 \\
(8.80)\end{array}$ & $\begin{array}{l}-82.79 \\
(13.86)\end{array}$ \\
\hline $2.5 \mathrm{M}$ & $\begin{array}{l}46.31 \\
(22.26)\end{array}$ & $\begin{array}{l}-85.54 \\
(26.73)\end{array}$ & $\begin{array}{l}-1.63 \\
(17.7 I)\end{array}$ & $\begin{array}{l}-42.98 \\
(I 3.5 I)\end{array}$ & $\begin{array}{l}50.63 \\
(13.25)\end{array}$ & $\begin{array}{l}-96.53 \\
(11.03)\end{array}$ & $\begin{array}{l}-5.91 \\
(7.94)\end{array}$ & $\begin{array}{l}-49.69 \\
(13.5 I)\end{array}$ \\
\hline $3.7 \mathrm{M}$ & $\begin{array}{l}42.13 \\
(17.29)\end{array}$ & $\begin{array}{l}-95.87 \\
(35.17)\end{array}$ & $\begin{array}{l}-7.72 \\
(22.00)\end{array}$ & $\begin{array}{l}-35.33 \\
(10.38)\end{array}$ & $\begin{array}{l}4 I .5 I \\
(8.96)\end{array}$ & $\begin{array}{l}-102.14 \\
(12.16)\end{array}$ & $\begin{array}{l}-8.20 \\
(5.24)\end{array}$ & $\begin{array}{l}-40.24 \\
(10.38)\end{array}$ \\
\hline $5 \mathrm{M}$ & $\begin{array}{c}30.48 \\
(22.95)\end{array}$ & $\begin{array}{l}-105.79 \\
(40.10)\end{array}$ & $\begin{array}{l}-14.88 \\
(22.74)\end{array}$ & $\begin{array}{l}-19.32 \\
(13.13)\end{array}$ & $\begin{array}{l}29.25 \\
(13.33)\end{array}$ & $\begin{array}{l}-105.03 \\
(9.26)\end{array}$ & $\begin{array}{l}-6.98 \\
(4.11)\end{array}$ & $\begin{array}{l}-28.11 \\
(13.13)\end{array}$ \\
\hline
\end{tabular}




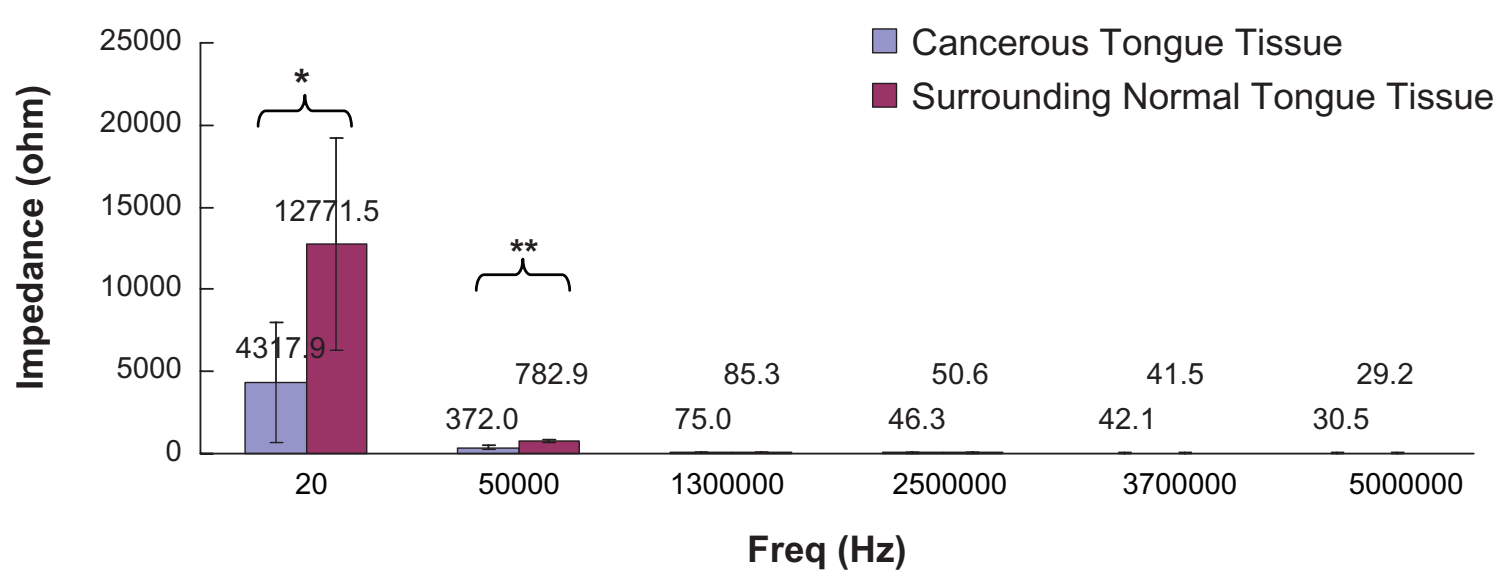

\section{Freq $(\mathrm{Hz})$}

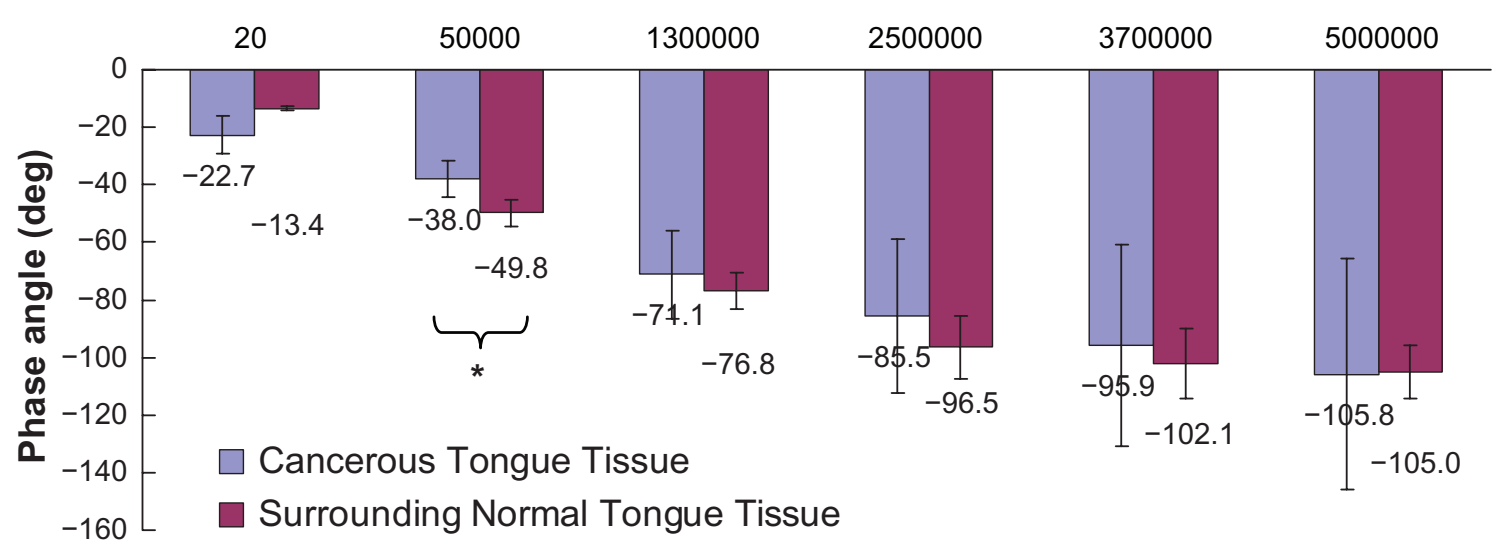

Figure 2 Impedance and phase angle of cancerous and surrounding normal tongue tissues measured at different frequencies. Results were expressed as means and standard deviations. Statistically significant differences between cancerous and surrounding normal tongue tissues were shown, with $P<0.05$ represented by* and $P<0.00$ I represented by**.

$20 \mathrm{~Hz}(\mathrm{ICC}=0.88)$ and that of real part of impedance at $50 \mathrm{kHz}(\mathrm{ICC}=0.83)$ and $5 \mathrm{MHz}(\mathrm{ICC}=0.87)$, exceeded 0.90 , which suggests they have exceeded the threshold for both good reliability and reasonable validity. Although the ICC $(3,1)$ for the surrounding NTT measurements of phase angle at $20 \mathrm{~Hz}$ and that of real part of impedance at $50 \mathrm{kHz}$ and $5 \mathrm{MHz}$ were smaller than 0.90 , they all exceeded 0.75 which suggests they have good reliability.

Impedance measurements can be in two-electrode configuration or four-electrode configuration. In this study, a four-electrode impedance measurement was employed as this led to the measured impedance being essentially independent of the contact impedance between electrode and tissue. Because a four-electrode configuration was utilized in this study and human tongue is small, the disposable probe and its sensing area should be as small as possible. In this study, the sensing area of the probe was about $9 \mathrm{~mm}^{2}(3 \times 3 \mathrm{~mm})$ with the probe size of $5 \mathrm{~mm}$ width, $3 \mathrm{~mm}$ thick and $100 \mathrm{~mm}$ long. This ensured the probe was capable of being placed in most parts of the human tongue.

Tongue cancer is usually associated with the squamous cell carcinoma (SCC). ${ }^{26} \mathrm{SCC}$ is a malignant neoplasm of mucosal origin ${ }^{27}$ and often causes abnormality of the covering mucosa of the oral cavity. ${ }^{28}$ In this study, $\alpha$ - and $\beta$-dispersion regions $(20 \mathrm{~Hz}-5 \mathrm{MHz})$ for tongue tissue measurement of the electrical properties $(Z, \theta, R$, and $X)$ was conducted. Our findings showed that not all the frequencies within the $\alpha$ - and $\beta$-dispersion regions were suitable for use in distinguishing the CTT and surrounding NTT. Only the electrical properties measurement at $20 \mathrm{~Hz}(\mathrm{Z}, \mathrm{R}$, and X measurements) and $50 \mathrm{kHz}(Z, \theta, \mathrm{R}$, and X measurement) could significantly distinguish the CTT and surrounding NTT. Results also showed 

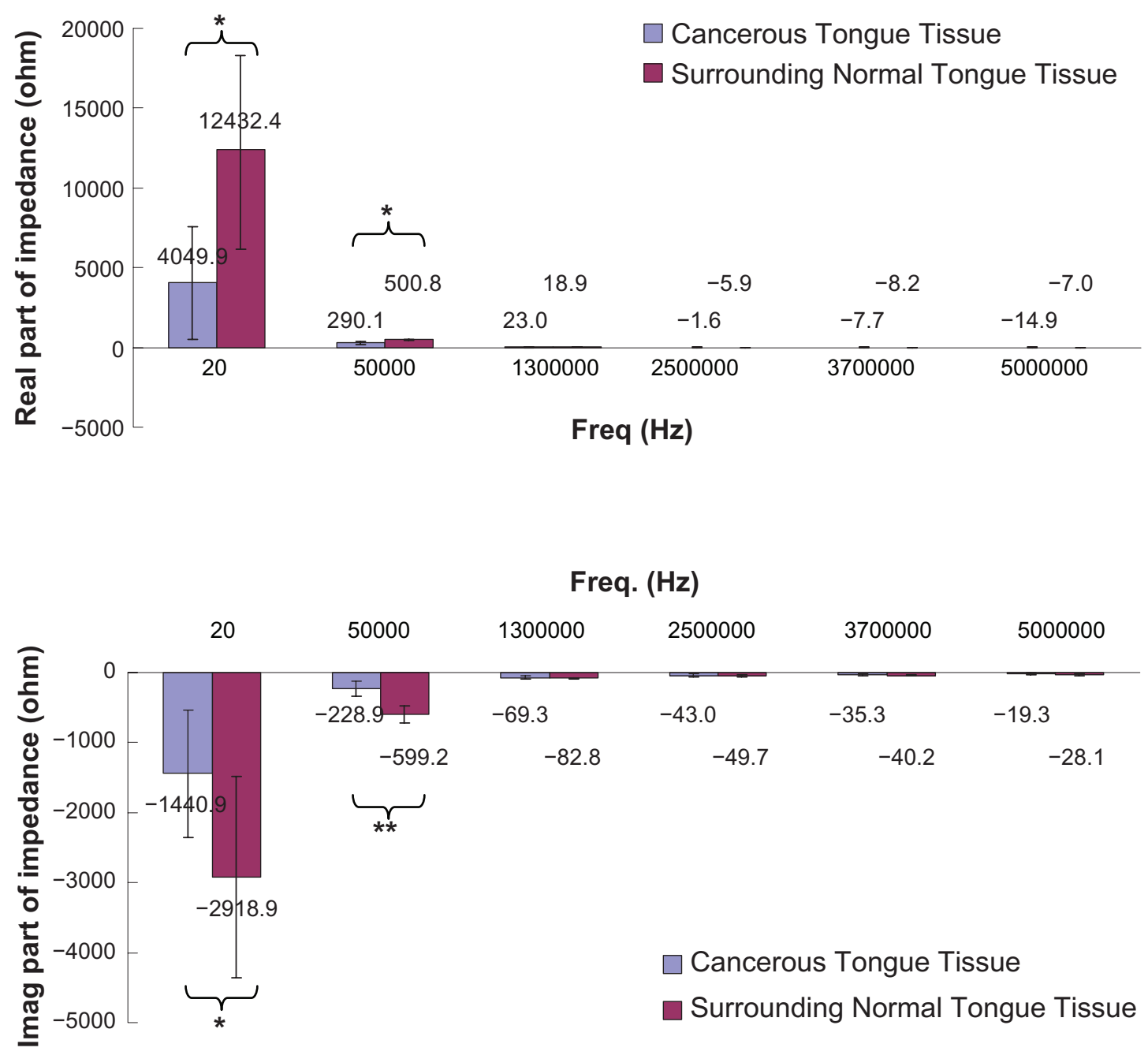

Figure 3 Real and imaginary part of impedance of cancerous and surrounding normal tongue tissues measured at different frequencies. Results were expressed as means and standard deviations. Statistically significant differences between cancerous and surrounding normal tongue tissues were shown, with $\mathrm{p}<0.05$ represented by* and $\mathrm{p}<0.00 \mathrm{I}$ represented by**.

that $\mathrm{Z}$ and $\mathrm{R}$ of CTT $(\mathrm{Z} \cong 4318 \Omega$ at $20 \mathrm{~Hz}$ and $372 \Omega$ at $50 \mathrm{kHz}$; $\mathrm{R} \cong 4050 \Omega$ at $20 \mathrm{~Hz}$ and $290 \Omega$ at $50 \mathrm{kHz}$ ) was significantly smaller (Z: a 3-fold decrease at $20 \mathrm{~Hz}$ and a 2-fold decrease at $50 \mathrm{kHz}$; R: a 3-fold decrease at $20 \mathrm{~Hz}$ and a 1.7-fold decrease at $50 \mathrm{kHz})$ than that of the surrounding NTT $(\mathrm{Z} \cong 12772 \Omega$ at $20 \mathrm{~Hz}$ and $783 \Omega$ at $50 \mathrm{kHz} ; \mathrm{R} \cong 12432 \Omega$ at $20 \mathrm{~Hz}$ and $501 \Omega$ at $50 \mathrm{kHz}$ ). This might be due to the abnormality of the covering mucosa of the CTT. A possible explanation for the changes observed might be that at low frequency $(<1 \mathrm{MHz})$ most of the current flows around the cell without being able to penetrate into the cell and the measured values of $\mathrm{Z}$ and $\mathrm{R}$ are dominated by contributions from the most superficial layer of the oral mucosa. In NTT, cells are well packed and attached to each other, therefore the current at low frequency has a very narrow and tortuous intercellular route to follow, which therefore has high resistance. However, cancer cells normally have a phenomenon of metastases, which have the opposite effects on resistance. CTT has a wide extracellular space because of the loss of intercellular connections, a universal characteristic of cancer leading to metastases, and this would be expected to decrease resistance.

$50 \mathrm{kHz}$ resulted in significant separation of CTT from surrounding NTT on the 4 electrical properties $(Z, \theta, R$, and $\mathrm{X}$ ) measurement while $20 \mathrm{~Hz}$ resulted in significant separation of CTT from surrounding NTT on only 3 electrical properties ( $\mathrm{Z}, \mathrm{R}$, and $\mathrm{X}$ ) measurement. Decision making based on 4 significant parameters is more reliable as compared to 3 significant parameters, and so $50 \mathrm{kHz}$ is suggested as the optimum frequency for distinguishing the CTT and surrounding NTT.

Our findings were similar to those in the literature reporting on the bioimpedance measurements of breast 
cancer. $^{9-12,17-20}$ These literatures reported that malignant breast tumors have typically lower electrical impedance than surrounding normal tissues. Our results are also in agreement with those reported by other researchers who found that cervical intraepithelial neoplasia normally has a lower electrical impedance than surrounding normal tissues. ${ }^{13-15}$ As shown in Figure 2, CTT had relatively lower electrical impedance than surrounding NTT. Therefore, it can be seen that cancerous tissue generally has lower electrical impedance than surrounding normal tissue.

Based on our findings, bioimpedance potentially provides a promising technique for squamous tongue cancer screening. It offers the benefits for high-risk patients who may suffer from tongue cancer to have regular tongue cancer screenings at home. For example, smokers, alcoholics, and people chewing betel nuts in Taiwan.

The advantage of this method, as a potential screening test over the current screening methods, is that: it has a relatively low-cost; provides instant (ie, real-time) results; requires little training; and therefore could be easily used in primary care or in developing countries where the organizational structure and economical factors limit national screening programs. The potential advantages of real-time screening tests include: a reduction in patient anxiety; improved patient compliance; and the ability to repeat inadequate tests immediately.

Research is ongoing to recruit more tongue cancer patients, at different stages of the disease, to reduce the standard deviation among data and increase reliability. The electrical properties measurement at different distances away from the regional edge of the cancerous tongue tissue and the electrical properties measurement of pre- and post-operative tongue cancer patients is also being studied.

In conclusion, significant separation of CTT from surrounding NTT could be achieved at $50 \mathrm{kHz}$ electrical properties $(Z, \theta, R$, and $X)$ measurement. ICC showed that all measurements had good reliability. It was also found that $Z$ and R of CTT were generally smaller than that of surrounding NTT. The advantage of this method as a potential screening test is that it can provide an immediate result and may be used by those with minimal training in the setting of primary care or in the developing world.

\section{Acknowledgments}

The authors wish to thank the patients who participated in this study. This work was supported by grants from the Taichung Veterans General Hospital and National Chi Nan University (TCVGH-NCNU-987908) Taichung, Taiwan,
Republic of China. Also, this work was partially supported by grants (NSC 98-2221-E-260-002- and NSC 98-2221-E260-024-MY3) from National Science Council, Taiwan, Republic of China.

\section{Disclosures}

The authors report no conflicts of interest relevant to this research.

\section{References}

1. Lumerman H, Freedman P, Kerpel S. Oral epithelial dysplasia and the development of invasive squamous cell carcinoma. Oral Surg Oral Med Oral Pathol Oral Radiol Endodontics. 1995;79:321-329.

2. Parkin DM, Bray F, et al. Global cancer statistics, 2002. CA Cancer J Clin. 2005;55:74-108.

3. Badizadegan K, Backman V, et al. Spectroscopic diagnosis and imaging of visible precancers. Faraday Discuss. 2004;126:265-279.

4. Staveren HJ van, Veen RLP van, et al. Classification of clinical autoflourescence spectra of oral leucoplakia using an artificial neural network: a pilot study. Oral Oncol. 2000;36:286-293.

5. Lau DP, Huang Z, et al. Raman spectroscopy for optical diagnosis in normal and cancerous tissue of the nasopharynx-preliminary findings. Lasers Surg Med. 2003;32:210-214.

6. Muller MG, Valdez TA, et al. Spectroscopic detection and evaluation of morphologic and biochemical changes in early human oral carcinoma. Cancer. 2003;97:1681-1692.

7. Pethig R. Dielectric properties of body tissues. Clin Phys Physiol Meas. 1987;8:A5-A12.

8. Blad B, Baldetorp B. Impedance spectra of tumor tissue in comparison with normal tissue:a possible clinical application for electrical impedance tomography. Physiol Meas. 1996;17:A105-A115.

9. Ohmine Y, Morimoto T, et al. Noninvasive measurement of the electrical bioimpedance of breast tumors. Anticancer Res. 2000:20: 1941-1946.

10. Morimoto T, Kimura S, et al. A study of the electrical bioimpedance of tumors. J Invest Surg. 1993;6:25-32.

11. Morimoto T, Kinouchi Y, et al. Measurement of the electrical bioimpedance of breast tumors. Eur Surg Res. 1990;22:86-92.

12. Singh B, Smith CW, Hughes R. In vivo dielectric spectrometer. Med Biol Eng Comput. 1979;17:45-60.

13. Abdul $\mathrm{S}$, Brown BH, et al. The use of electrical impedance spectroscopy in the detection of cervical intraepithelial neoplasia. Int $J$ Gynecol Cancer. 2006;16:1823-1832.

14. Abdul S, Brown BH, et al. A clinical study of the use of impedance spectroscopy in the detection of cervical intraepithelial neoplasia (CIN). Gynecol Oncol. 2005;99:S64-S66.

15. Brown BH, Tid JA y, et al. Relation between tissue structure and imposed electrical current flow in cervical neoplasia. Lancet. 2000;355:892-895.

16. FDA Premarket Approval database. http://www.fda.gov/cdrh/pma/ pmaapr99.html. P970033, Accessed February 2010.

17. Stelter J, Wtorek J, et al. Complex permittivity of breast tumor tissue. Proceedings of 10th International Conference on Electrical Bio-Impedance, Barcelona. 5-9 April 1998. p. 59-62.

18. Jossinet J. Variability of impedivity in normal and pathological breast tissue. Med Biol Eng Comput. 1996;34:346-350.

19. Heinitz J, Minet O. Dielectric properties of female breast tumors. Proceedings of Ninth International Conference on Electrical BioImpedance, Heidelberg. 26-30 September 1995. p. 356-359.

20. Campbell AM, Land DV. Dielectric properties of female breast tissue measured in vitro at 3.2 GHz. Phys Med Biol. 1992;37:193-210.

21. Scholz B, Anderson R. On electrical impedance scanning-principles and simulations. Electromedica. 2000;68:35-44. 
22. Fricke H, Morse S. The electrical capacity of tumors of the breast. J Cancer Res. 1926;10:340-376.

23. Rabbat A. Tissue resistivity. In: Webster JG, editor. Electrical impedance tomography. Bristol and New York: IOP Publishing; 1990. p. 8-20.

24. Portney L, Watkins M. Foundations of Clinical Research: applications to practice. 2nd ed. New Jersey: Prentice Hall Health; 2000.

25. Portney L, Watkins M. Foundations of Clinical Research:applications to practice. 2nd ed. New Jersey:Prentice Hall Health; 2000. p. 565.
26. Neville B. Oral and maxillofacial pathology, 1st ed. Philadelphia: WB Saunders Co; 1995. p. 295-304.

27. Langlass R, Miller C. Colour atlas of common oral diseases, 2 nd ed. Philadelphia PA: Lippincott Williams \& Wilkins; 1998. p. 93-128.

28. Suei Y, Tanımato K, et al. Mucosal condition of the oral cavity and sites of origin of squamous cell carcinoma. J Oral Maxillofac Surg. 1995;53:144-147

\section{Publish your work in this journal}

The International Journal of Nanomedicine is an international, peerreviewed journal focusing on the application of nanotechnology in diagnostics, therapeutics, and drug delivery systems throughout the biomedical field. This journal is indexed on PubMed Central,

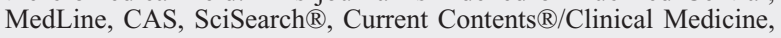

Journal Citation Reports/Science Edition, EMBase, Scopus and the Elsevier Bibliographic databases. The manuscript management system is completely online and includes a very quick and fair peer-review system, which is all easy to use. Visit http://www.dovepress.com/ testimonials.php to read real quotes from published authors. 